\title{
Isolation and Characterisation of Cellulose Nanofibre and Lignin from Oil Palm Empty Fruit Bunches
}

\author{
Saharman Gea * ${ }^{0}$, Amir Hamzah Siregar, Emma Zaidar, Mahyuni Harahap ${ }^{\infty}$, \\ Denny Pratama Indrawan and Yurika Almanda Perangin-Angin
}

Department of Chemistry, Faculty of Mathematics and Natural Sciences, Universitas Sumatera Utara, Jalan Bioteknologi No.1., Medan 20155, Indonesia; siregar_amirhamzah@yahoo.com (A.H.S.); ema3@usu.ac.id (E.Z.); harahap.mahyuni@gmail.com (M.H.); dennypratama96@gmail.com (D.P.I.); yurikaalmanda183@gmail.com (Y.A.P.-A.)

* Correspondence: s.gea@usu.ac.id

Received: 1 April 2020; Accepted: 11 May 2020; Published: 15 May 2020

\begin{abstract}
A study on isolation and characterisation of cellulose nanofibre (CNF) and lignin was conducted to expand the application of CNF and lignin from oil palm biomass. CNF was extracted by steam explosion and the by-product was precipitated to obtain lignin by using the soda-pulping method. The concentrations of $\mathrm{NaOH}$ used for $\mathrm{CNF}$ by-product precipitation were $2 \%, 4 \%$, and $6 \%$. The morphology of CNF and lignin was characterised using scanning electron microscopy (SEM). The nanofibre of CNF with dimension between $50 \mathrm{~nm}$ and $100 \mathrm{~nm}$ was investigated using transmission electron microscopy (TEM). The functional group was observed using Fourier-transform infrared (FTIR) spectroscopy, showing that CNF had the structure of cellulose-I. In addition, the chemical structures of isolated and commercial lignin were analysed using ${ }^{1} \mathrm{H}-\mathrm{NMR}$ spectrometry. CNF had a 72\% crystallinity index characterised by X-ray diffraction (XRD), while lignin showed an amorphous form. The characterisation of isolated lignin was compared with commercial lignin. The two lignins had similar particle size distribution from 1 to $100 \mu \mathrm{m}$. From UV-visible analysis, the lignin had aromatic rings/non-conjugated phenolic groups. The morphology of isolated lignin was rough and flaky. Commercial lignin was in powder form with near-spherical morphology. Thermogravimetric analysis (TGA) of CNF showed $30 \%$ of residue at $600{ }^{\circ} \mathrm{C}$. The results showed a simple method to isolate $\mathrm{CNF}$ and lignin from oil palm empty fruit bunches.
\end{abstract}

Keywords: cellulose nanofibre; lignin; palm empty fruit bunch; steam explosion; soda-pulping

\section{Introduction}

The synthesis of fine chemicals and bio-based functional materials has attracted huge attention and created significant public value with the increasing of environmental and ecological concerns due to the use of petroleum-based chemicals and products [1]. Cellulose nanofibre (CNF) is extracted from cellulose (the most abundant natural polymer in the world). It has desirable properties such as low density, non-toxicity, and biodegradability. Additionally, it has unique properties such as high mechanical strength, reinforcement capabilities, and tunable self-assembly in aqueous media, arising from its unique shape, size, surface chemistry, and high degree of crystallinity [2].

CNF has a Young's modulus between 20 and 50 GPa with surface areas of hundreds of square meters per gram [3]. These properties cause the biopolymer to have many new promising properties and applications [4,5]. Scientists have started to produce innovative materials from CNF for novel and emerging applications to tackle environmental problems originating from an abundance of renewable biomass. Several studies have reported the isolation of CNF from biomass, such as CNF from bagasse using acid and ball milling method [6], from tomato peels using acidified sodium chloride [7], and from 
a banana peel using high ultrasonication and chemical treatment [8]. The biomass can provide an excellent alternative to petroleum and other valuable commodities. CNF is used to produce a variety of high-value products with low environmental and societal impact [9]. It has been reported that the presence of CNF in a polymer matrix improves the mechanical properties due to the large specific surface area and high aspect ratio. For example, Balea et al. reported that CNF improved mechanical recycled paper properties by $15.1 \%$ with the addition of $3 \mathrm{wt} \%$ CNF [10]. In addition, CNF isolated from corn organosolv pulp increased the tensile index of recycled paper by $20 \%$ [11].

Lignin is the most dominant aromatic polymer on Earth and the second most abundant natural resource after cellulose [12]. It comprises up to $20 \%$ to $30 \%$ of the weight of woody plants $[13,14]$. Lignin, a by-product of pulp and paper industry, is globally produced at approximately 70 million tons annually [15]. This polymer has been developed for valuable applications such as macromolecular toughening agents for epoxy resin, surfactants for nanomaterials, and carbon nanosheets for high-capacitance supercapacitors. Lignin is considered as an ideal carbon fibre precursor due to its availability in nature, affordability, and bituminous coal-like structure [16]. It has been reported that a Kraft hardwood lignin and an organic-purified hardwood lignin have potential as precursors for low-cost carbon fibre. Lignin-based carbon fibre has a tensile strength of 0.51 GPa and a tensile modulus of 28.6 GPa [17]. In addition, carbon fibre from acetylated lignin has a tensile modulus, strength, and strain-to-failure values of $52 \pm 2 \mathrm{GPa}, 1.04 \pm 0.10 \mathrm{GPa}$, and $2.0 \pm 0.2 \%$, respectively [18].

Carbon fibre consists of approximately $92 \%$ carbon, which is obtained through carbonisation. It is a lightweight material, has low density, and has good mechanical properties (stronger than steel and aluminum). The demand of carbon fibre increased significantly from 33 million tons in 2010 to 64 million tons in 2016, and it is projected to increase to 120 million tons in 2022 [19]. This is due to the increase in the use of carbon fibre, starting from sport equipment, aircraft, and advanced engineering application. Nowadays, the precursor of carbon fibre has been developed from natural resources because of environmental concern. Lignin-based carbon fibre is currently in the "Research and Development" stage. Some studies have reported the usage of lignin as a carbon fibre precursor. For example, Zhang and Zhao carbonised lignin to produce three-dimensional porous carbon [20], while Mainka reported the use of lignin as an alternative precursor for sustainable automotive carbon [21]. However, the Young's modulus and strength of the carbon fibre is still low. It is expected that by blending CNF and lignin, the mechanical properties of lignin-based carbon fibre can be increased. In addition, the production cost of lignin-based carbon fibre is estimated to be about $\$ 4-5 / 1 b$, compared to that of petroleum-based carbon fibre, $\$ 10 / \mathrm{lb}$. at commercial scale [22].

In this study, we are interested in isolating lignin and CNF from palm empty fruit bunches (PEFB) with a simple method (the flowchart is presented in Figure 1). PEFB consist of cellulose (65\%), lignin $(29.2 \%)$, hemicellulose $(28.8 \%)$, and extractive substances $(3.7 \%)$. There are many studies that reported the utilisation of PEFB-based cellulose, for example, pulp production, activated carbon, and potassium fertiliser for oil palm planting [23]. However, lignin derived from by-product is still less utilised. In this study, we isolated CNF by steam explosion and lignin was extracted from the by-product through the soda-pulping precipitation method. Lignin and CNF of PEFB have the potential to be used as precursors for carbon fibre and reinforcement materials. 


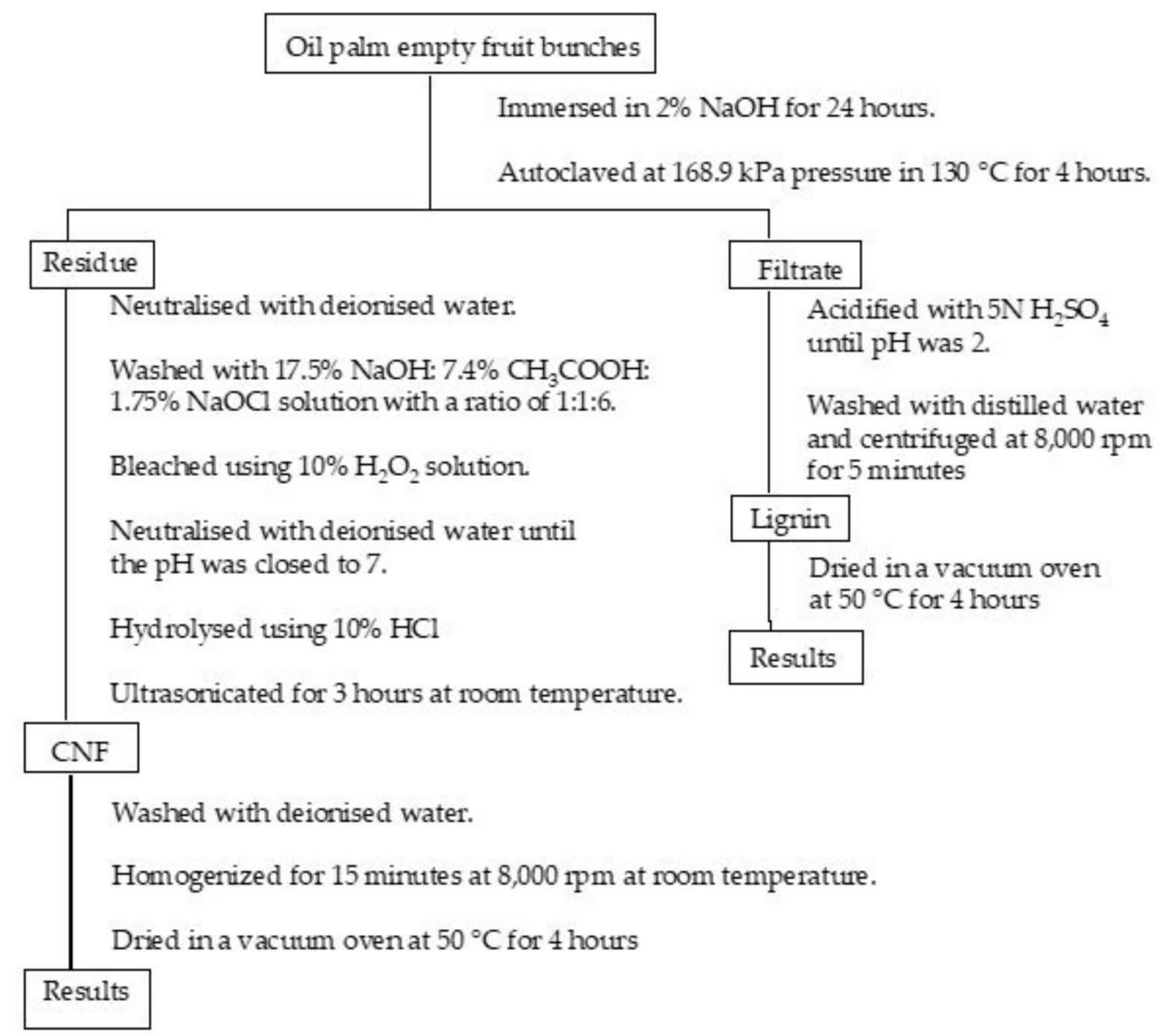

Figure 1. A flowchart of isolating cellulose nanofibre and lignin from oil palm empty fruit bunches.

\section{Materials and Methods}

\subsection{Materials}

In this study, palm empty fruit bunches (PEFB) were used as a raw material to produce cellulose nanofibre (CNF) and lignin. PEFB were obtained from palm plantation managed by Universitas Sumatera Utara. Some chemical reagents used such as $\mathrm{NaOH}, \mathrm{CH}_{3} \mathrm{COOH}, \mathrm{NaOCl}, \mathrm{H}_{2} \mathrm{O}_{2}, \mathrm{HCl}, \mathrm{H}_{2} \mathrm{SO}_{4}$ were purchased from Merck (Damstadt, Germany).

\subsection{Isolation and Purification of Cellulose Nanofibre}

Cellulose nanofibre (CNF) was isolated by steam explosion based on our previous work [24]. Firstly, PEFB fibre was cut into small pieces and immersed in $2 \% \mathrm{NaOH}$ for $24 \mathrm{~h}$. The suspension was then filtered. The residue was autoclaved at $168.9 \mathrm{kPa}$ pressure in $130{ }^{\circ} \mathrm{C}$ for $4 \mathrm{~h}$ to collect $\mathrm{CNF}$, and the filtrate was kept to isolate the lignin. The residue collected was neutralised with deionised water. After that, the sample was washed with $17.5 \% \mathrm{NaOH}: 7.4 \% \mathrm{CH}_{3} \mathrm{COOH}: 1.75 \% \mathrm{NaOCl}$ solution with a ratio of 1:1:6. The fibre was bleached using $10 \% \mathrm{H}_{2} \mathrm{O}_{2}$ solution and neutralised with deionised water until the $\mathrm{pH}$ was close to 7 . The bleached fibre was hydrolysed using $10 \% \mathrm{HCl}$ and ultrasonicated for $3 \mathrm{~h}$ at room temperature. Finally, CNF obtained was washed with deionised water and homogenised for $15 \mathrm{~min}$ at $8000 \mathrm{rpm}$ at room temperature until the fibre was suspended. The suspension was filtered and $\mathrm{CNF}$ was dried in a vacuum oven at $50^{\circ} \mathrm{C}$ for $4 \mathrm{~h}$. The drying sample was coded as CNF. 


\subsection{Isolation and Purification of Lignin}

$\mathrm{NaOH}$ was used to immerse PEFB fibre with various concentrations of $2 \%, 4 \%$, and $6 \%$ for $24 \mathrm{~h}$. The filtered PEFB suspension was acidified with $5 \mathrm{~N} \mathrm{H}_{2} \mathrm{SO}_{4}$ until $\mathrm{pH}$ was 2 . Next, acidified lignin was washed with distilled water and centrifuged at $8000 \mathrm{rpm}$ for $5 \mathrm{~min}$. The lignin was dried in a vacuum oven at $50{ }^{\circ} \mathrm{C}$ for $4 \mathrm{~h}$. The products were coded as lignin_NaOH2\%, lignin_NaoH4\%, and lignin_NaOH6\% for lignin obtained from PEFB fibre immersed in $2 \%, 4 \%$ and $6 \% \mathrm{NaOH}$, respectively.

\subsection{Characterisation}

\subsubsection{Scanning Electron Microscopy}

Morphology of the samples was analysed by using a scanning electron microscopy (SEM, Hitacho TM3030, JEOL, Ltd., Tokyo, Japan) operating at $20 \mathrm{kV}$. The sample was first coated with a thin layer of gold before analysis to reduce charges during analysis.

\subsubsection{Transmission Electron Microscopy}

A $0.01 \mathrm{CNF} w / v \%$ in distilled water was dispersed using a homogeniser. The suspension was then deposited on carbon-coated electron microscope grids and stained negatively with a drop of uranyl acetate. The sample was allowed to dry at room temperature before analysis. After that, it was observed with a transmission electron microscopy JEOL/EO JEM-1400 (TEM, JEOL, Ltd, Tokyo, Japan) operated at an accelerating voltage of $100 \mathrm{kV}$.

\subsubsection{Fourier Transform Infra-Red Characterisation}

The functional groups in CNF and lignin were investigated using a FTIR Spectrometer (FTIR, Nicolet 380, Thermo Scientific, Boston, MA, USA). The samples for FTIR were prepared using KBr and a sample with comparison of 100:1. The instrument was operated in transmission mode with a wavelength of $400-4000 \mathrm{~cm}^{-1}$, resolution of $4 \mathrm{~cm}^{-1}$, and 50 scans.

\subsubsection{X-ray Diffraction Analysis}

X-ray diffraction (XRD, Bruker D8 advanced X-ray diffractometer, Bruker Optic GmbH, Ettlingen, Germany), patterns were investigated using a Shimadzu XRD-6100 diffractometer with $\mathrm{Cu}-\mathrm{K} \alpha$ radiation $(\lambda=0.154 \mathrm{~nm})$ at scanning rate of $2^{\circ} / \mathrm{min}, 40 \mathrm{kV}$ voltage and $200 \mathrm{~mA}$ current. The crystallinity of CNF was determined based on the Segal method.

\subsubsection{Particle Size Distribution}

Particle size distributions of commercial and isolated lignin were analysed using a particle size analyser (LA-910, Horiba LA-910, Horiba Ltd, Kyoto, Japan). A diluted lignin solution was dispersed in distilled water and sonicated for $30 \mathrm{~min}$. A few drops of the suspension were introduced to the dispersion unit in the instrument. The data were acquired over five cycles.

\subsubsection{UV-Visible Spectroscopy}

UV-visible spectra were recorded on an ultraviolet/visible spectrophotometer (UV 1800 series, Shimadzu Scientific Instrument, Kyoto, Japan). A $5 \mathrm{mg}$ of sample was dissolved in $0.1 \mathrm{~mol} / \mathrm{L} \mathrm{NaOH}$ solution $(10 \mathrm{~mL})$. One millilitre of the aliquot was diluted to $10 \mathrm{~mL}$ with distilled water and the absorbance in between 250 and $400 \mathrm{~nm}$ wavelength was measured.

\subsection{7. ${ }^{1} \mathrm{H}-\mathrm{NMR}$}

${ }^{1} \mathrm{H}-\mathrm{NMR}$ spectra were recorded on an Agilent $500 \mathrm{MHz}$ (NMR, Agilent Technology, Santa Clara, CA, USA) at a frequency of $500 \mathrm{MHz}$ at room temperature with an acquisition time of 0.011 . 


\subsubsection{Thermogravimetric Analysis}

The mass-loss property of the materials was characterised using a thermogravimetric analyser (DTA/TG Exsstar SII 7300, Hitachi medical system, Tokyo, Japan). The sample was heated from 25 to $600{ }^{\circ} \mathrm{C}$ with a heating rate of $10^{\circ} \mathrm{C} /$ minute under nitrogen atmosphere.

\section{Results}

\subsection{Morphological Properties of Cellulose Nanofibre and Lignin}

Figure 2a shows the morphology of CNF with 100× magnification. CNF morphology is seen as single fibres sticking to one another. This is probably due to hemicellulose, lignin, and pectin removal during chemical treatment. In addition, Figure 3 shows that the fibre has dimensions between 50 and $100 \mathrm{~nm}$, which is calculated using ImageJ analysis. It is also seen that the CNF looks like whiskers. The results indicated that the CNF obtained has a nanoscale [25]. Another study reported that $\mathrm{CNF}$ isolated from a pineapple leaf using steam explosion had an interconnected web-like structure with a width between $5 \mathrm{~nm}$ and $60 \mathrm{~nm}$ [26]. The morphology of lignin precipitated with various $\mathrm{NaOH}$ concentrations is shown in Figure $2 \mathrm{~b}-\mathrm{j}$. The morphology of lignin_NaOH2\%, lignin_NaOH4\%, and lignin_NaOH6\% is observed as rough and flaky, whereas commercial lignin was in powder form with near-spherical morphology. The differences between isolated and commercial lignin morphology are present because of the different procedures used in manufacturing commercial lignin and lignin extracted in this study. From 1000 times magnification, there were slight pores on the surface of lignin_NaOH6\% which were not observed in other isolated lignins. The presence of pores enhanced the dispersion of lignin with other polymers since they promote penetration of polymer into lignin molecules [27]. 


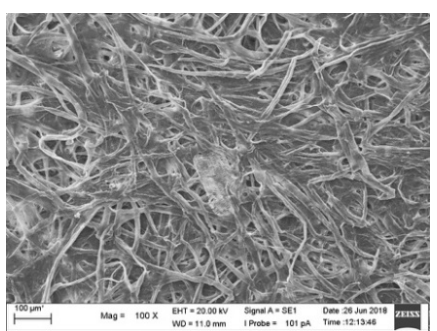

(a)

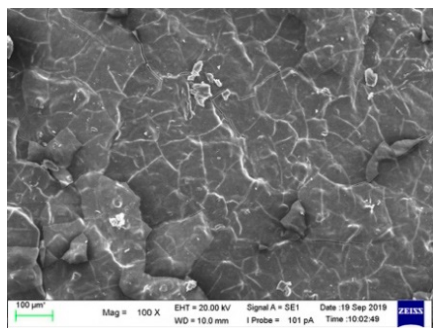

(d)

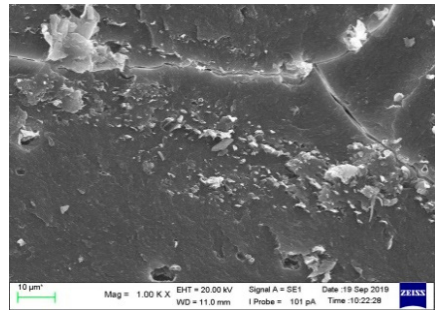

(g)

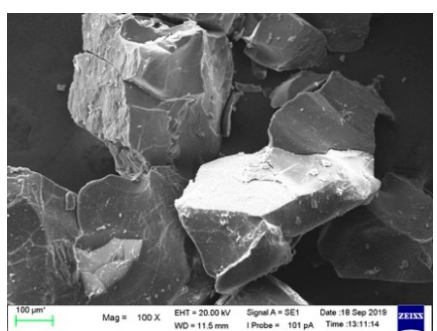

(b)

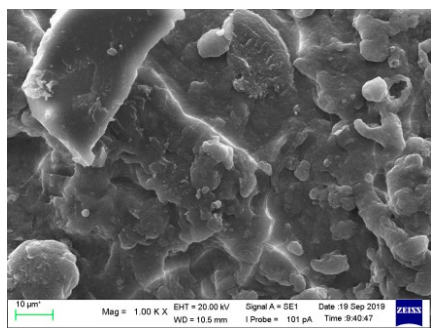

(e)

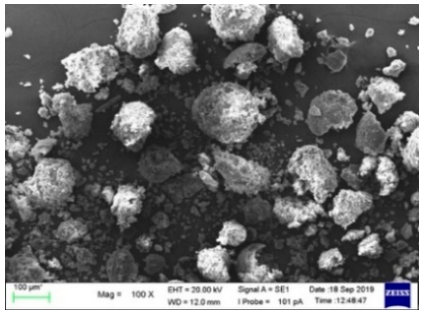

(h)

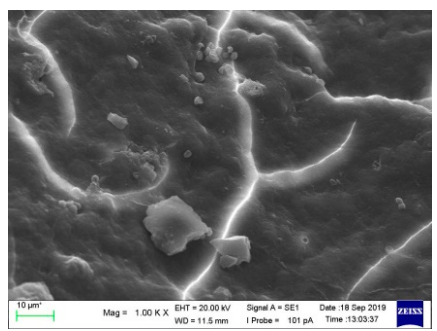

(c)

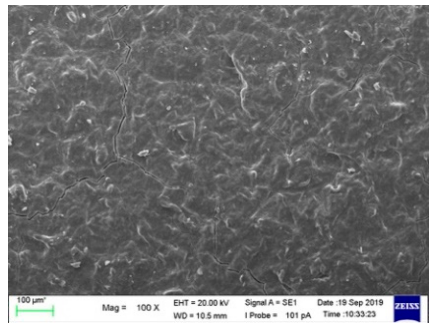

(f)

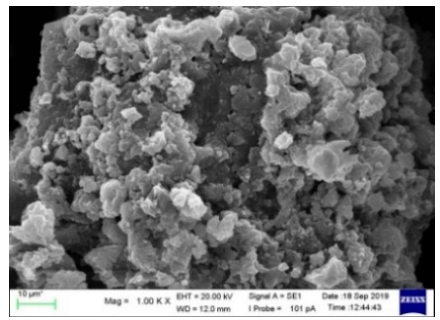

(i)

Figure 2. The morphology of: (a) cellulose nanofibre (CNF), (b,c) lignin_NaOH2\%, (d,e) lignin_NaOH4\%, (f,g) lignin_NaOH6\%, and (h,i) commercial lignin.

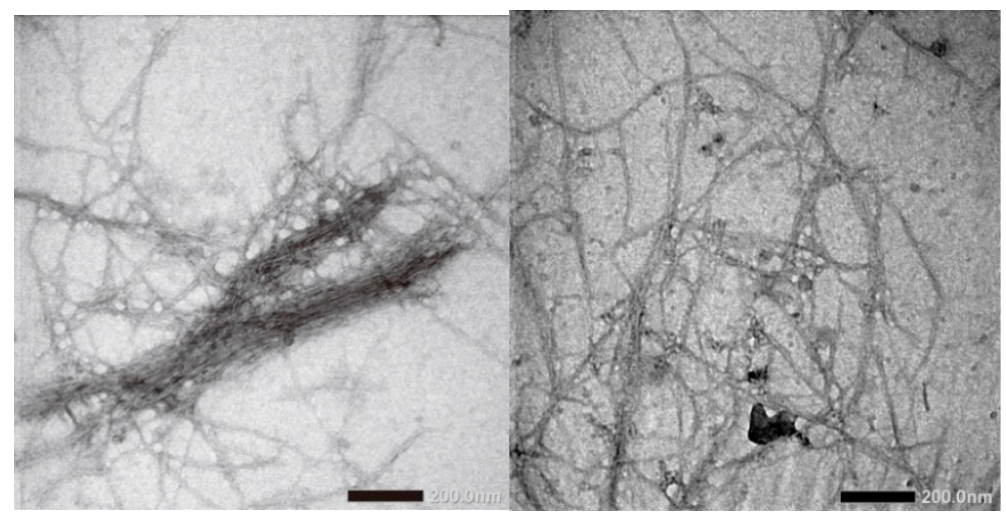

Figure 3. TEM images of CNF from palm empty fruit bunches produced by steam explosion.

\subsection{FTIR and UV Spectra}

CNF and lignin FTIR spectral analyses were done to identify the functional groups present in the materials. FTIR spectra for these polymers are shown in Figure 4. 


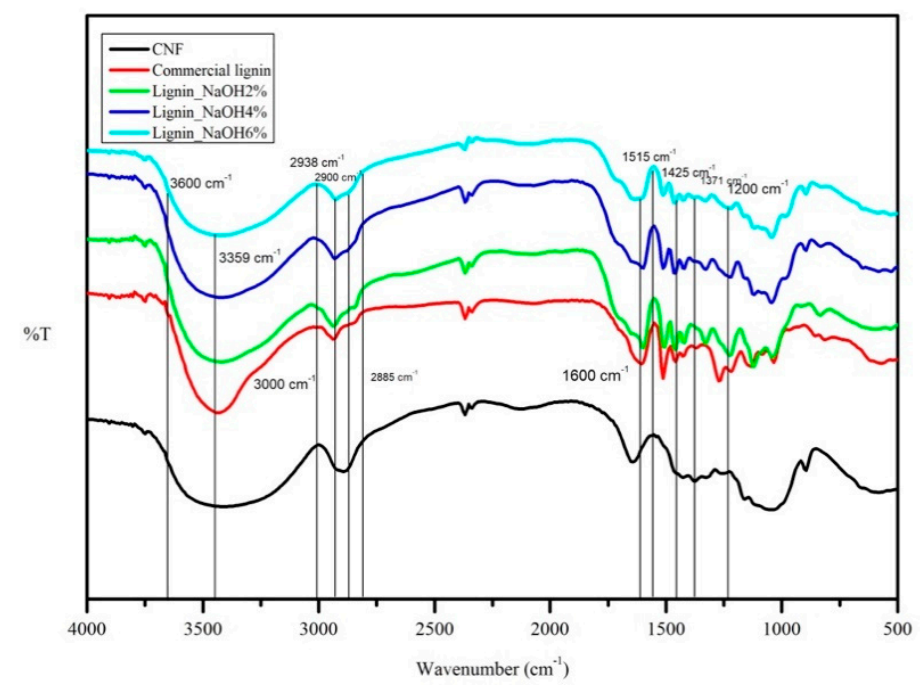

Figure 4. FTIR spectra of $\mathrm{CNF}$, lignin_NaOH2\%, lignin_NaOH4\%, lignin_NaOH6\%, and commercial lignin.

With reference to Figure 4, the CNF absorption band at $3359 \mathrm{~cm}^{-1}$ represented hydrogen-bonded (O-H) stretching and C-H stretching was shown at $2900 \mathrm{~cm}^{-1}$. The presence of $\mathrm{O}-\mathrm{H}$ bending that absorbed water was seen at $1600 \mathrm{~cm}^{-1}$. The absorption bands at $1371 \mathrm{~cm}^{-1}$ and $1200 \mathrm{~cm}^{-1}$ represented $\mathrm{C}-\mathrm{H}$ in $-\mathrm{O}(\mathrm{C}=\mathrm{O})-\mathrm{CH}_{3}$ and $\mathrm{C}-\mathrm{O}$ stretching of acetyl group in cellulose, respectively $[28,29]$. Both isolated and commercial lignin showed absorption bands at $1600 \mathrm{~cm}^{-1}, 1515 \mathrm{~cm}^{-1}$, and $1425 \mathrm{~cm}^{-1}$ corresponding to aromatic ring vibrations of the phenylpropene (C9) skeleton [30]. Hydroxyl groups in aromatic and aliphatic structures were seen in a wide absorption range between 3600 and $3000 \mathrm{~cm}^{-1}$. C-H stretching in methyl and methylene groups of the side chain appeared at $2938 \mathrm{~cm}^{-1}$ absorption for all lignin. The peak at $2885 \mathrm{~cm}^{-1}$ corresponded to $\mathrm{C}-\mathrm{H}$ stretching in aromatic methoxy group [31]. The attribution of the absorption peak for CNF and lignin is summarised in Table 1.

Table 1. FTIR spectral assignments for CNF and lignin [30,32,33].

\begin{tabular}{|c|c|c|}
\hline Wavenumber $\left(\mathrm{cm}^{-1}\right)$ & \multicolumn{2}{|c|}{$\begin{array}{l}\text { Attribution to the Band } \\
\text { CNF Lignin }\end{array}$} \\
\hline 3430 & & $\mathrm{O}-\mathrm{H}$ stretching of hydroxyl groups \\
\hline 3278-3495 & O-H stretching & \\
\hline 2940-2840 & & $\mathrm{C}-\mathrm{H}$ stretching of aliphatic and aromatic structure \\
\hline 2890 & H-C-H stretching (alkyl, aliphatic) & \\
\hline $1765-1705$ & & $\mathrm{C}=\mathrm{O}$ stretching of carboxylic groups \\
\hline $1720-1740$ & $\mathrm{C}=\mathrm{O}$ stretching (carbonyl) & \\
\hline 1640 & Fibre-OH (absorbed water) & \\
\hline 1600 & & C-C stretching of aromatic skeleton \\
\hline $1611,1517,1425$ & & Vibrations of aromatic rings \\
\hline 1429 & $\begin{array}{l}\mathrm{HCH} \text { and } \mathrm{OCH} \text { bending vibration } \\
\text { (methylene group) }\end{array}$ & \\
\hline 1371,1200 & $\mathrm{CH}$ deformation vibration $\left(\mathrm{CH}_{3}\right.$ or $\mathrm{OH}$ in plane) & \\
\hline $1328,1271,1114$ & & Vibrations of $\mathrm{C}-\mathrm{H}$ bonds in aromatic rings \\
\hline $1270-1232$ & C-O-C ether bond (aryl-alkyl ether) & \\
\hline 1220 & & $\mathrm{C}-\mathrm{O}(\mathrm{H})+\mathrm{C}-\mathrm{O}(\mathrm{Ar})$ stretching \\
\hline $1170-1082$ & $\begin{array}{l}\text { C-O-C antisymmetric bridge stretching (Pyranose } \\
\text { ring skeletal) }\end{array}$ & \\
\hline 1108 & $\mathrm{OH}(\mathrm{C}-\mathrm{OH})$ & \\
\hline $1071-1067$ & C-O stretching & \\
\hline 1041-1054 & $\begin{array}{l}\text { C-O symmetric stretching (C-O of } \\
\text { primary alcohol) }\end{array}$ & \\
\hline $896-915$ & $\begin{array}{l}\mathrm{COC}, \mathrm{CCO} \text {, and } \mathrm{CCH} \text { deformation and } \\
\text { stretching vibration }\end{array}$ & \\
\hline 834 & & Vibrations of $\mathrm{C}-\mathrm{H}$ bonds in aromatic rings \\
\hline 700 & $\mathrm{CH}_{2}$ vibrations & \\
\hline
\end{tabular}

UV spectroscopy was attributed to investigate lignin variability distribution and purity. Lignin consists of several functional chemical groups such as methoxy, carbonyl, carboxyl, and hydroxyl 
(phenolic and alcoholic). However, these groups are dependent on its original resources and the isolation procedure applied. Figure 5 shows UV absorption spectra of commercial and isolated lignin (lignin_NaOH2\%, lignin_NaOH4\% and lignin_NaOH6\%). As seen on Figure 4, there was no significant difference within the acquired UV spectra for all lignin samples. All lignin samples had maximum absorption at around $280 \mathrm{~nm}$ which indicated the presence of aromatic rings/non-conjugated phenolic groups in the lignin structure [34,35]. In addition, UV-vis spectra for CNF dispersion in deionised water showed optimum absorption at a wavelength of $\sim 280 \mathrm{~nm}$.

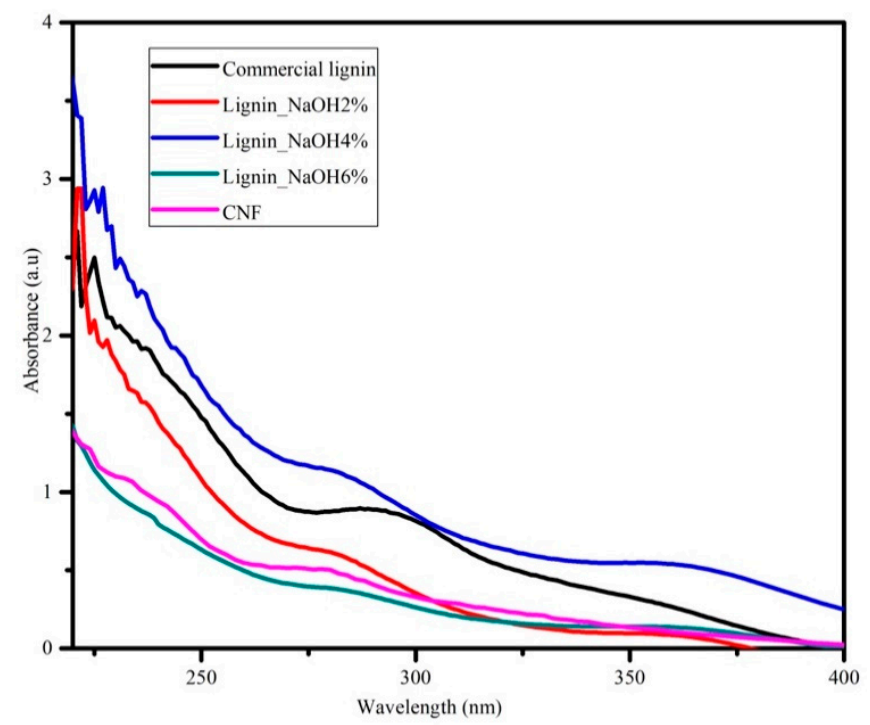

Figure 5. Ultraviolet-visible (UV-vis) analysis of commercial lignin, lignin_NaOH2\%, lignin_NaOH4\%, lignin_NaOH6\%, and CNF.

\section{3. ${ }^{1} \mathrm{H}-\mathrm{NMR}$ of Pure Lignin}

The chemical structures of isolated and commercial lignin were analysed using ${ }^{1} \mathrm{H}-\mathrm{NMR}$ spectrometry. The lignin sample ${ }^{1} \mathrm{H}-\mathrm{NMR}$ result is presented in Figure 6. Protons in phenolic hydroxyl can be seen in the signals between 8.0 and $9.0 \mathrm{ppm}$. The integration of signals in the 6.2-7.6 ppm range could be attributed to aromatic and vinyl protons in syringyl (S) and guaiacyl (G) units. Aliphatic protons appeared in the signals from 4.2 to $5.6 \mathrm{ppm}$. The signal at around $3.8 \mathrm{ppm}$ was related to the proportion of the $G$ and $S$ units. The sharp signals at $3.4 \mathrm{ppm}$ and $2.5 \mathrm{ppm}$ were attributed to a water contaminant and DMSO-d6 solvent, respectively. Water contaminants appeared in both isolated and commercial lignin samples, as the sample was not well-dried before analysis; meanwhile, the DMSO-d6 used was not $100 \%$ pure. Finally, protons in saturated aliphatics were seen in the 2.3-1.2 ppm range.

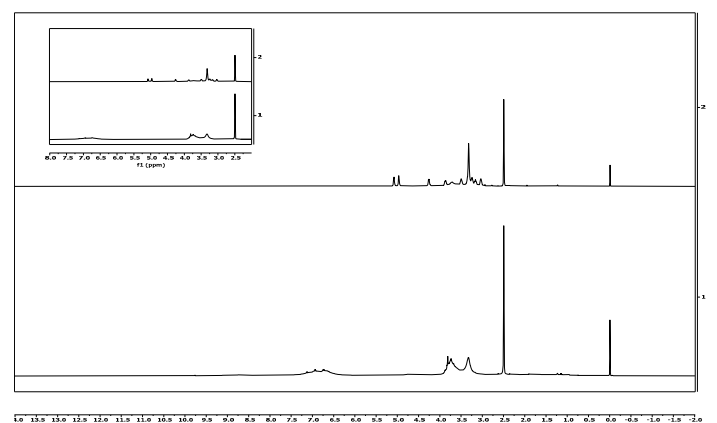

Figure 6. Signals of proton NMR of isolated lignin (above) and commercial lignin (below). 


\subsection{X-Ray Diffraction Analysis}

X-ray diffraction (XRD) analysis was performed to investigate the lignin properties in more detail as well as the crystallinity of CNF. Isolated and commercial lignin showed amorphous patterns (Figure 7). From Figure 7, a crystallographic plane of native cellulose structure was assigned at the peak range between $21.90^{\circ}$ and $22.20^{\circ} 2 \theta$. All of the diffractogram is described in more detail as follows: $14.5^{\circ}-15.3^{\circ} 2 \theta$ reflection attributed to the (1-10) crystallographic plane, the $15.7^{\circ}-16.30^{\circ} 2 \theta$ reflection attributed to the (110) crystallographic plane, the $18.30^{\circ}-18.40^{\circ}$ reflection attributed to the amorphous phase, and the $21.90^{\circ}-22.20^{\circ} 2 \theta$ reflection attributed to the (200) crystallographic plane of cellulose I $[29,36]$. Based on the Segal equation, the crystallinity index of the CNF was calculated at $72 \%$.

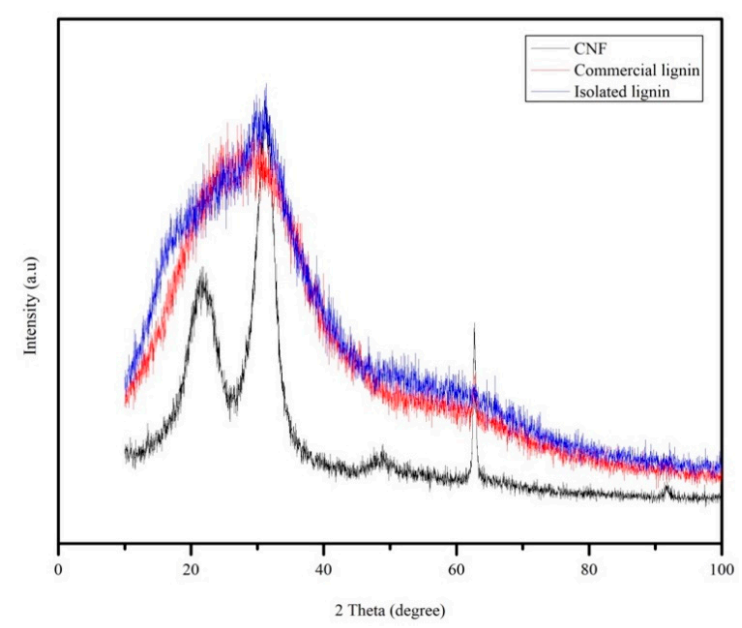

Figure 7. XRD pattern of CNF, commercial, and isolated lignin.

\subsection{Particle Size Analysis of Lignin}

The particle size analysis of lignin is shown in Figure 8. Particle size distribution of commercial lignin was between 1 and $300 \mu \mathrm{m}$, which is almost the same as lignin_NaOH2\% and lignin_NaOH4\%, while lignin_NaOH6\% had the smallest particle size, from 1-30 $\mu \mathrm{m}$. At the sample preparation step, lignin was first dispersed in deionised water and sonicated using a homogeniser at $300 \mathrm{rpm}$ with various durations. Lignin_NaOH6\% was sonicated for the longest time, hence the slight shift of its distribution to lower sizes. The large particle size of lignin may also be correlated to poor lignin solution in common organic solvent. It was found that lignin solution precipitated when it was stored for a longer time. 


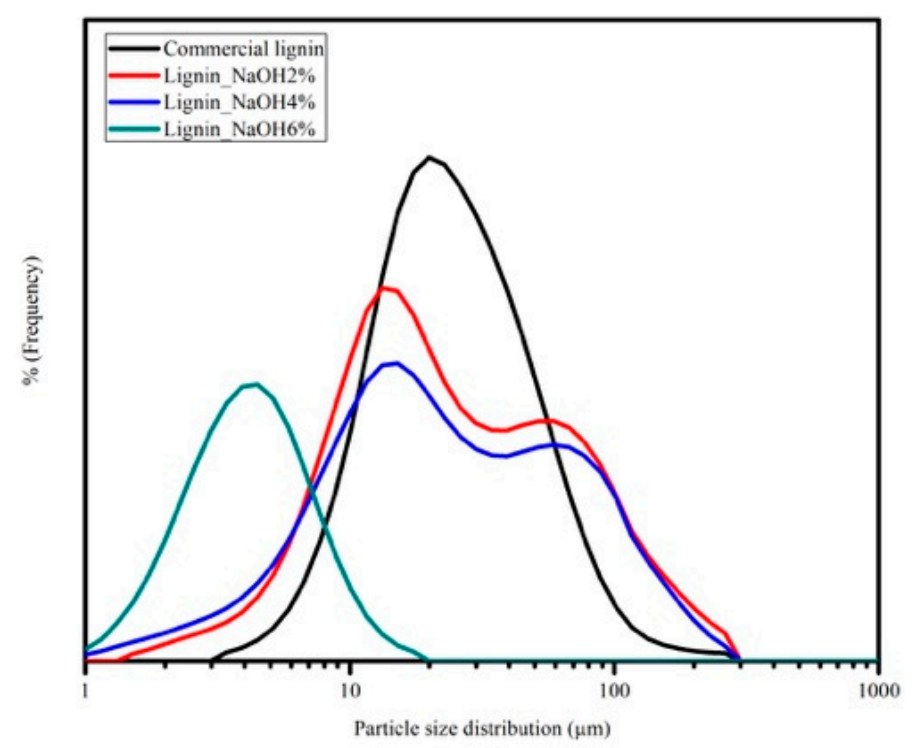

Figure 8. Particle size distribution of commercial lignin, lignin_NaOH2\%, lignin_NaOH4\%, and lignin_NaOH6\%.

\subsection{Thermogravimetric Analysis}

Thermogravimetric analysis (TGA) was done to analyse the thermal stability of CNF, commercial lignin, and isolated lignin. The thermal characteristic results are summarised in Table 2, while the thermogravimetric traces for lignin and CNF are presented in Figure 9.

Table 2. Thermal characteristic of CNF and lignin samples.

\begin{tabular}{|c|c|c|c|c|c|c|}
\hline \multirow{2}{*}{ Sample } & \multicolumn{2}{|c|}{ First Decomposition } & \multicolumn{2}{|c|}{ Second Decomposition } & \multicolumn{2}{|c|}{ Third Decomposition } \\
\hline & Residual Mass (\%) & $\mathrm{T}_{\max }\left({ }^{\circ} \mathrm{C}\right)$ & Residual Mass (\%) & $\mathrm{T}_{\max }\left({ }^{\circ} \mathrm{C}\right)$ & Residual Mass (\%) & $\mathrm{T}_{\max }\left({ }^{\circ} \mathrm{C}\right)$ \\
\hline Lignin_NaOH2\% & 93.0 & 105.7 & 66.4 & 350.6 & 3.5 & 600.5 \\
\hline Lignin_NaOH4\% & 91.4 & 105.6 & 54.9 & 350.4 & 0.8 & 600.8 \\
\hline Lignin_NaOH6\% & 91.2 & 105.5 & 49.6 & 350.7 & 1.7 & 600.6 \\
\hline $\begin{array}{l}\text { Commercial } \\
\text { lignin }\end{array}$ & 96.1 & 105.3 & 76.9 & 350.9 & 1.9 & 600.5 \\
\hline NFC & 99.8 & 105.8 & 35.5 & 400.0 & 30.2 & 600.0 \\
\hline
\end{tabular}

Thermogravimetric traces showed thermal degradation temperatures which were attributed to samples weight loss. In Figure 8, the lignin TGA curve showed a three-stage processing time function. First, the dehydration of samples started from room temperature to $100{ }^{\circ} \mathrm{C}$. There was $1 \%-3 \%$ weight loss for isolated lignin and $4 \%$ for commercial lignin. At this stage, the moisture content in lignin was removed. Second, the thermal degradation of lignin samples was in the temperature range of 225 to $350{ }^{\circ} \mathrm{C}$. There was almost $50 \%$ weight loss for isolated lignin, and the most prominent trend is seen for lignin_NaOH6\%. However, the mass decrease for commercial lignin at this step was only approximately $25 \%$. Finally, lignin samples lost almost all of their weight at $600{ }^{\circ} \mathrm{C}$. There were remaining residual masses of $3.5 \%, 0.8 \%, 1.7 \%$, and $1.9 \%$ for lignin_NaOH2\%, lignin_NaOH4\%, lignin_NaOH6\%, and commercial lignin, respectively. 


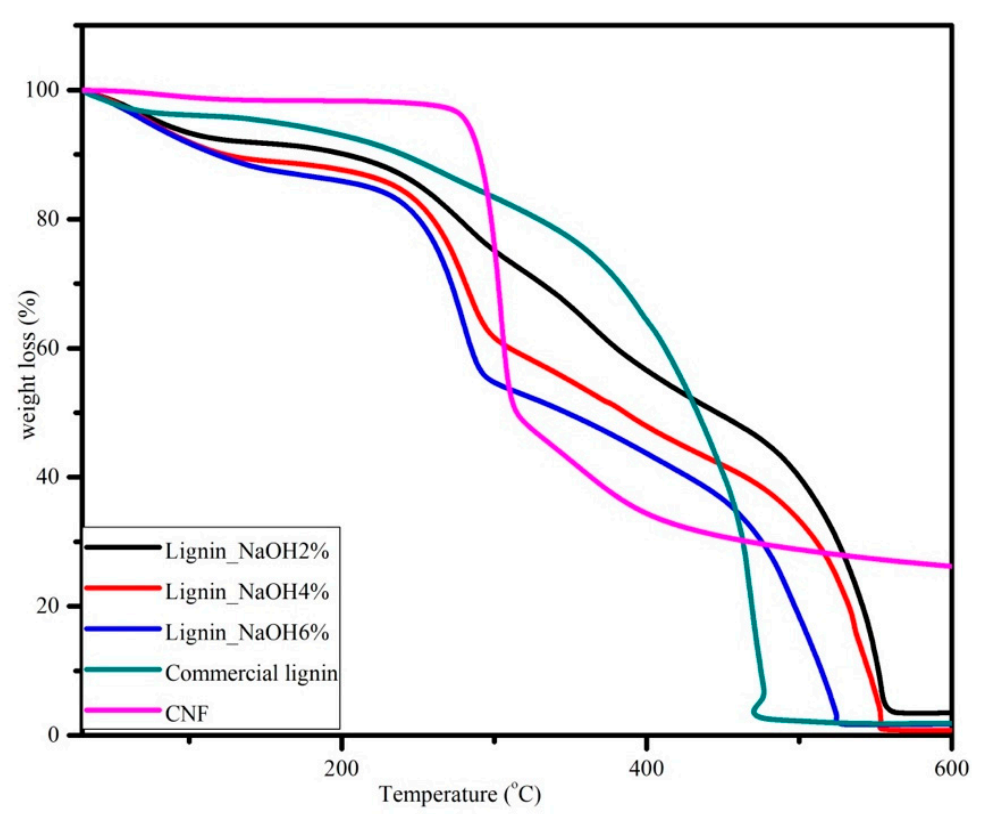

Figure 9. Thermogravimetric analysis curves for $\mathrm{CNF}$, commercial, and isolated lignin with $10^{\circ} \mathrm{C} /$ minute heating rate.

The TGA trace for CNF also shows three distinct regions. The first one was between room temperature and $100{ }^{\circ} \mathrm{C}$ where $\mathrm{CNF}$ was dehydrated. The second region was observed from 270 to $400^{\circ} \mathrm{C}$ where there was decomposition of $\mathrm{CNF}$ to its monomers, D-glucopyranose. Last, decomposition was completed at $600{ }^{\circ} \mathrm{C}$ with approximately $30 \%$ carbon yield, which was higher than that of lignin. From the data, thermal decomposition of the CNF was higher than that of lignin. Increasing of the crystallinity index of material shifted the thermal decomposition to a higher temperature [37]. The same value also has been reported from different raw materials, such as Alfa fibre [38] and wood [39]. The crystalline regions of CNF act as barriers for the heat transfer, hence they improve the thermal stability of CNF [36].

\section{Conclusions}

Cellulose nanofibre (CNF) and lignin from palm empty fruit bunches was successfully isolated without by-product. In this study, the isolation of CNF was achieved successfully using steam explosion and lignin using soda pulping methods. It was shown that the method used is effective and efficient. CNFs have diameters between 50 and $100 \mathrm{~nm}$ with $72 \%$ crystallinity index. Commercial lignin was in powder form with near-spherical morphology, whereas isolated lignin has flaky and rough morphology. Particle size distributions of commercial and isolated lignin are almost the same, between 1 and $300 \mu \mathrm{m}$. From UV-visible analysis, lignin has aromatic rings/non-conjugated phenolic groups. Thermal properties demonstrated that CNF has higher thermal stability than lignin associated with high crystallinity of CNF (72\%). It can be concluded that lignin and CNF of PEFB have the potential to be used as precursors for carbon fibre and reinforcement materials.

Author Contributions: Conceptualisation, S.G. and M.H.; methodology, D.P.I. and Y.A.P.-A.; software, M.H. and E.Z.; validation, S.G. and M.H.; formal analysis, S.G., A.H.S., and M.H.; investigation, E.Z. and Y.A.P.-A.; resources, E.Z. and A.H.S.; data curation, S.G., A.H.S., and M.H.; writing-original draft preparation, S.G. and A.H.S.; writing-review and editing, E.Z. and M.H.; visualisation, D.P.I.; supervision, S.G.; project administration, Y.A.P.-A.; funding acquisition, S.G., A.H.S., and E.Z. All authors have read and agreed to the published version of the manuscript.

Funding: This research was funded by the Indonesian Ministry of Research and Technology for the support funds from DRPM 2019 PDUPT scheme with contract number 159/UNS.2.3.1/PPM/KP-DRPM/2019. 
Acknowledgments: Author would like to thank Rector Universitas Sumatera Utara for providing research facility through Postgraduate Facility, Universitas Sumatera Utara.

Conflicts of Interest: The authors declare no conflicts of interest.

\section{References}

1. Thomas, B.; Raj, M.C.; Athira, B.K.; Rubiyah, H.M.; Joy, J.; Moores, A.; Drisko, G.L.; Sanchez, C. Nanocellulose, a Versatile Green Platform: From Biosources to Materials and Their Applications. Chem. Rev. 2018, 118, 11575-11625. [CrossRef]

2. Habibi, Y. Key advances in the chemical modification of nanocelluloses. Chem. Soc. Rev. 2014, 43, 1519-1542. [CrossRef]

3. Usov, I.; Nyström, G.; Adamcík, J.; Handschin, S.; Schütz, C.; Fall, A.; Bergström, L.; Mezzenga, R. Understanding nanocellulose chirality and structure-properties relationship at the single fibril level. Nat. Commun. 2015, 6, 7564. [CrossRef] [PubMed]

4. Balea, A.; Fuente, E.; Blanco, A.; Negro, C. Nanocelluloses: Natural-Based Materials for Fiber-Reinforced Cement Composites. A Critical Review. Polymers 2019, 11, 518. [CrossRef] [PubMed]

5. Balea, A.; Fuente, E.; Monte, M.C.; Merayo, N.; Campano, C.; Negro, C.; Blanco, A. Industrial Application of Nanocelluloses in Papermaking: A Review of Challenges, Technical Solutions, and Market Perspectives. Molecules 2020, 25, 526. [CrossRef]

6. Sofla, M.R.K.; Brown, R.; Tsuzuki, T.; Rainey, T.J. A comparison of cellulose nanocrystals and cellulose nanofibres extracted from bagasse using acid and ball milling methods. Adv. Nat. Sci. Nanosci. Nanotechnol. 2016, 7, 35004. [CrossRef]

7. Jiang, F.; Hsieh, Y.-L. Cellulose nanocrystal isolation from tomato peels and assembled nanofibers. Carbohydr. Polym. 2015, 122, 60-68. [CrossRef] [PubMed]

8. Xie, J.-L.; Hse, C.Y.; De Hoop, C.F.; Hu, T.; Qi, J.; Shupe, T.F. Isolation and characterization of cellulose nanofibers from bamboo using microwave liquefaction combined with chemical treatment and ultrasonication. Carbohydr. Polym. 2016, 151, 725-734. [CrossRef]

9. Negro, C.; Balea, A.; Luis, J.; Campano, C.; Fuente, E.; Conception, M.; Blanco, A. Nanocellulose and Its Potential Use for Sustainable Industri. Latin Am. Appl. Res. 2020, 50, 59-198.

10. Balea, A.; Merayo, N.; Fuente, E.; Negro, C.; Delgado-Aguilar, M.; Mutjé, P.; Blanco, A. Cellulose nanofibers from residues to improve linting and mechanical properties of recycled paper. Cellulose 2017, 25, 1339-1351. [CrossRef]

11. Balea, A.; Merayo, N.; Fuente, E.; Delgado-Aguilar, M.; Mutje, P.; Blanco, A.; Negro, C. Valorization of Corn Stalk by the Production of Cellulose Nanofibers to Improve Recycled Paper Properties. Bioresources 2016, 11, 3416-3431. [CrossRef]

12. Tanase-Opedal, M.; Espinosa, E.; Rodriguez, A.; Chinga-Carrasco, G. Lignin: A Biopolymer from Forestry Biomass for Biocomposites and 3D Printing. Materials 2019, 12, 3006. [CrossRef] [PubMed]

13. Ragauskas, A.; Beckham, G.T.; Biddy, M.; Chandra, R.; Chen, F.; Davis, M.; Davison, B.H.; Dixon, R.A.; Gilna, P.; Keller, M.; et al. Lignin Valorization: Improving Lignin Processing in the Biorefinery. Sciences 2014, 344, 1246843. [CrossRef] [PubMed]

14. Grosjean, R.; Le Godec, Y.; Delacroix, S.; Gouget, G.; Beaunier, P.; Ersen, O.; Ihiawakrim, D.; Courac, A.; Chaneac, C.; Portehault, D. A high pressure pathway toward boron-based nanostructured solids. Dalton Trans. 2018, 47, 7634-7639. [CrossRef]

15. Liu, W.-J.; Jiang, H.; Yu, H.-Q. Thermochemical conversion of lignin to functional materials: A review and future directions. Green Chem. 2015, 17, 4888-4907. [CrossRef]

16. Liu, W.; Yao, Y.; Fu, O.; Jiang, S.; Fang, Y.; Wei, Y.; Lu, X. Lignin-derived carbon nanosheets for high-capacitance supercapacitors. RSC Adv. 2017, 7, 48537-48543. [CrossRef]

17. Baker, D.A.; Gallego, N.C.; Baker, F.S. On the characterization and spinning of an organic-purified lignin toward the manufacture of low-cost carbon fiber. J. Appl. Polym. Sci. 2011, 124, 227-234. [CrossRef]

18. Zhang, M.; Ogale, A.A. Carbon fibers from dry-spinning of acetylated softwood kraft lignin. Carbon 2014, 69, 626-629. [CrossRef]

19. Holmes, M. Global carbon fibre market remains on upward trend. Reinf. Plast. 2014, 58, 38-45. [CrossRef] 
20. Zhang, W.; Lin, H.; Lin, Z.; Yin, J.; Lu, H.; Liu, D.; Zhao, M. 3 D Hierarchical Porous Carbon for Supercapacitors Prepared from Lignin through a Facile Template-Free Method. ChemSusChem 2015, 8, 2114-2122. [CrossRef]

21. Mainka, H.; Täger, O.; Körner, E.; Hilfert, L.; Busse, S.; Edelmann, F.T.; Herrmann, A.S. Lignin - an alternative precursor for sustainable and cost-effective automotive carbon fiber. J. Mater. Res. Technol. 2015, 4, 283-296. [CrossRef]

22. Milbrandt, A.; Booth, S. Carbon Fiber from Biomass; Clean Energy Manufacturing Analysis Center: Golden, CO, USA, 2016.

23. Chang, S.H. An overview of empty fruit bunch from oil palm as feedstock for bio-oil production. Biomass Bioenergy 2014, 62, 174-181. [CrossRef]

24. Gea, S.; Zulfahmi, Z.; Yunus, D.; Andriayani, A.; Hutapea, Y.A. The Isolation of Nanofibre Cellulose from Oil Palm Empty Fruit Bunch Via Steam Explosion and Hydrolysis with $\mathrm{HCl}$ 10\%. J. Phys. Conf. Ser. 2018, 979, 012063. [CrossRef]

25. Pesaran, M.; Amoabediny, G.; Yazdian, F. Effect of Cultivation Time and Medium Condition in Production of Bacterial Cellulose Nanofiber for Urease Immobilization. Int. J. Polym. Sci. 2015, 2015, 1-8. [CrossRef]

26. Cherian, B.M.; Leao, A.L.; De Souza, S.F.; Thomas, S.; Pothen, L.A.; Kottaisamy, M. Isolation of nanocellulose from pineapple leaf fibres by steam explosion. Carbohydr. Polym. 2010, 81, 720-725. [CrossRef]

27. Van de Pas, D.; Hickson, A.; Donaldson, L.; Lloyd-Jones, G.; Tamminen, T.; Fernyhough, A.; Mattinen, M.L. Characterization of Fractionated Lignins Polymerized by Fungal Laccases. BioResources 2011, 6, 1105-1121.

28. Ashori, A.; Babaee, M.; Jonoobi, M.; Hamzeh, Y. Solvent-free acetylation of cellulose nanofibers for improving compatibility and dispersion. Carbohydr. Polym. 2014, 102, 369-375. [CrossRef]

29. Žepič, V.; Poljanšek, I.; Oven, P.; Škapin, A.S. Effect of Drying Pretreatment on the Acetylation of Nanofibrillated Cellulose. Eff. Dry. Pretreat. Acetylation Nanofibrillated Cellul. 2015, 10, 8148-8167.

30. Chen, J.; Liu, C.; Wu, S.; Liang, J.; Lei, M. Enhancing the quality of bio-oil from catalytic pyrolysis of kraft black liquor lignin. RSC Adv. 2016, 6, 107970-107976. [CrossRef]

31. Abdelaziz, O.Y.; Hulteberg, C.P. Physicochemical Characterisation of Technical Lignins for Their Potential Valorisation. Waste Biomass Valorization 2016, 8, 859-869. [CrossRef]

32. Ding, R.; Wu, H.; Thunga, M.; Bowler, N.; Kessler, M.R. Processing and characterization of low-cost electrospun carbon fibers from organosolv lignin/polyacrylonitrile blends. Carbon 2016, 100, 126-136. [CrossRef]

33. Harahap, M.; Hararak, B.; Khan, I.; Pandita, S.; Saharman, G. Wet-spinning of Cellulose Acetate Reinforced with Acetylated Nano-crystalline Cellulose as Carbon Fibre Precursors. IOP Conf. Ser. Mater. Sci. Eng. 2019, 553, 012038. [CrossRef]

34. Alzagameem, A.; Khaldi-Hansen, B.; Büchner, D.; Larkins, M.; Kamm, B.; Witzleben, S.T.; Schulze, M.; El Khaldi-Hansen, B. Lignocellulosic Biomass as Source for Lignin-Based Environmentally Benign Antioxidants. Molecules 2018, 23, 2664. [CrossRef] [PubMed]

35. Wang, J.; Deng, Y.; Qian, Y.; Qiu, X.; Ren, Y.; Yang, D. Reduction of lignin color via one-step UV irradiation. Green Chem. 2016, 18, 695-699. [CrossRef]

36. Poletto, M.; Ornaghi, H.; Zattera, A.J.; Júnior, H.L.O. Native Cellulose: Structure, Characterization and Thermal Properties. Materials 2014, 7, 6105-6119. [CrossRef] [PubMed]

37. Lamaming, J.; Hashim, R.; Leh, C.P.; Sulaiman, O. Properties of cellulose nanocrystals from oil palm trunk isolated by total chlorine free method. Carbohydr. Polym. 2017, 156, 409-416. [CrossRef]

38. Trache, D.; Donnot, A.; Khimeche, K.; Benelmir, R.; Brosse, N. Physico-chemical properties and thermal stability of microcrystalline cellulose isolated from Alfa fibres. Carbohydr. Polym. 2014, 104, 223-230. [CrossRef]

39. Chen, W.; Yu, H.; Liu, Y.; Chen, P.; Zhang, M.; Hai, Y. Individualization of cellulose nanofibers from wood using high-intensity ultrasonication combined with chemical pretreatments. Carbohydr. Polym. 2011, 83, 1804-1811. [CrossRef]

(C) 2020 by the authors. Licensee MDPI, Basel, Switzerland. This article is an open access article distributed under the terms and conditions of the Creative Commons Attribution (CC BY) license (http://creativecommons.org/licenses/by/4.0/). 